\title{
The Efficacy of Shielding Systems for Reducing Operator Exposure during Neurointerventional Procedures: A Real-World Prospective Study
}

\author{
(D)T.R. Miller, (D). Zhuo, (D) G. Jindal, (D) R. Shivashankar, (D) Beaty, and DD. Gandhi
}

\begin{abstract}
BACKGROUND AND PURPOSE: Neurointerventional surgery may expose patients and physician operators to substantial amounts of ionizing radiation. Although strategies for reducing patient exposure have been explored in the medical literature, there has been relatively little published in regards to decreasing operator exposure. The purpose of this study was to evaluate the efficacy of shielding systems in reducing physician exposure in a modern neurointerventional practice.
\end{abstract}

MATERIALS AND METHODS: Informed consent was obtained from operators for this Health Insurance Portability and Accountability Act-compliant, institutional review board-approved study. Operator radiation exposure was prospectively measured during 60 consecutive neurointerventional procedures from October to November 2013 using a 3-part lead shielding system. Exposure was then evaluated without lead shielding in a second 60-procedure block from April to May 2014. A radiation protection drape was randomly selected for use in half of the cases in each block. Two-way analysis of covariance was performed to test the effect of shielding systems on operator exposure while controlling for other covariates, including procedure dose-area product.

RESULTS: Mean operator procedure dose was $20.6 \mu$ Sv for the entire cohort and $17.7 \mu$ Sv when using some type of shielding. Operator exposure significantly correlated with procedure dose-area product, but not with other covariates. After we adjusted for procedure dose-area product, the use of lead shielding or a radiation protection drape significantly reduced operator exposure by $45 \%(F=12.54, P<$ $.0001)$ and $29 \%(F=7.02, P=.009)$, respectively. The difference in protection afforded by these systems was not statistically significant $(P=$ .46), and their adjunctive use did not provide additional protection.

CONCLUSIONS: Extensive lead shielding should be used as much as possible in neurointerventional surgery to reduce operator radiation exposure to acceptable levels. A radiation protection drape is a reasonable alternative when standard lead shielding is unavailable or impractical to use without neglecting strategies to minimize the dose.

ABBREVIATIONS: $\mathrm{BMI}=$ body mass index; $\mathrm{PKA}=$ air kerma area product

A dvances in endovascular technology have led to the increasing use of minimally invasive, neurointerventional procedures for the diagnosis and treatment of cerebrovascular disease. While the efficacy of these fluoroscopically guided examinations is well-established, there is growing concern regarding the exposure of patients and medical personnel to ionizing radiation. Prior reports have demonstrated that exposure of patients and workers may not be negligible during interventional neuroradiology procedures, likely due to the complexity of some inter-

Received September 1, 2016; accepted after revision October 12.

From the Departments of Diagnostic Radiology, Neuroradiology (T.R.M., J.Z., G.J. R.S., D.G.), and Neurosurgery (N.B.), University of Maryland Medical Center, Baltimore, Maryland.

Please address correspondence to Timothy R. Miller, MD, University of Maryland Medical Center, Department of Radiology, 22 South Greene St, Baltimore, MD 21201; e-mail: tmiller5@umm.edu

http://dx.doi.org/10.3174/ajnr.A5038 ventions and the use of digital subtraction angiography and biplane fluoroscopy. ${ }^{1-7}$ Patient exposure may be high enough to result in deterministic effects such as skin erythema and epilation, while both patients and physician operators are potentially at risk from the stochastic effects of this radiation, namely carcinogenesis. ${ }^{8-16}$

Although multiple reports in the literature detail the risks of patient exposure to ionizing radiation during neurointerventional procedures, little has been published regarding exposure of the treating physician operators. Furthermore, the few reports available have either included a relatively small number of cases performed by a few experienced neurointerventionalists or, alternatively, have focused on quantifying the degree of protection afforded by personal protective equipment, such as lead glasses or caps. ${ }^{1-4,17,18}$ While the use of such equipment remains an essential component of an overall strategy to protect medical personnel from scatter radiation, an equally important approach is to reduce the amount of scatter radiation 
reaching the physician operator. The latter may be achieved by minimizing the use of ionizing radiation in neurointerventions as much as clinically feasible and by the adjunctive deployment of shielding systems in the angiosuite. Strategies for minimizing radiation use in neurointerventional surgery have recently been described in detail by several groups and include the use of low-dose fluoroscope settings. ${ }^{19-22}$ However, the efficacy of shielding systems in neurointerventional surgery has largely remained unstudied.

We therefore elected to prospectively evaluate operator exposure to scatter ionizing radiation in our neurointerventional practice while using various shielding systems.

\section{MATERIALS AND METHODS}

The institutional review board approved the research protocol for this single-center, HIPAA-compliant study. Operator radiation exposure was prospectively measured during 2 blocks of 60 consecutive neuroangiography procedures performed in roughly 6-week periods from October to November 2013 and April to May 2014. Physician operators participating in the study included attending neurointerventional radiologists $(n=3)$ and physician trainees specializing in the field $(n=2)$. All physician operators wore standard personal protective equipment during the study, including a lead vest and skirt and a thyroid shield. Written and verbal informed consent was obtained from physician operators. Patient consent was not obtained because their clinical care and radiation dose were unaffected by the research protocol.

During each 60-procedure block, operator exposure was measured during all neuroangiography procedures performed on an Artis zee biplane fluoroscopy unit (Siemens, Erlangen, Germany), consisting of two $40 \times 30 \mathrm{~cm}$ flat panel image detectors in the anteroposterior and lateral planes. Along with operator radiation dose, fluoroscopy time, air kerma area product (PKA), procedure type (diagnostic versus intervention/treatment), and patient body mass index (BMI) were recorded for all procedures. Operator skin dose was measured by a personal electronic dosimeter (DMC 300; Mirion Technologies, Irvine California), which measures $\mathrm{Hp}(10)$, with a measurement range of $15 \mathrm{keV}$ to $7 \mathrm{MeV}$ for $\mathrm{x}$-rays and gamma rays, a dose range from $1 \mu \mathrm{Sv}$ to $10 \mathrm{~Sv}$, and an accuracy of at least $\pm 20 \%$ (typical, $\pm 10 \%$ ). Body mass index was obtained from the patient's medical record. The specific type of intervention was not recorded (eg, aneurysm coiling, mechanical thrombectomy) because it was thought that other factors, including vessel tortuosity, plaque burden, and lesion morphology, would also play a critical role in determining overall procedure complexity. Consequently, our study design accounted for procedure complexity by taking into account the overall amount of ionizing radiation used during the procedure, as reflected by the PKA.

During the first 60 consecutive procedures, the personal dosimeter was attached to the left collar of the primary operator on top of the individual's lead vest and thyroid shield. If $>1$ physician participated in the procedure, the dosimeter was transferred between operators to ensure that it was always located on the primary operator standing closest to the fluoroscope. The dosimeter was left in the angiosuite on the patient's upper right thigh during all powerinjected DSA runs while physician operators stood in the control room to avoid unnecessary radiation exposure. This procedure was used to standardize the relationship between measured operator exposure and the PKA. The dosimeter remained on the primary operator's left collar during all hand-injected DSA runs.

Standard radiation lead shielding was used in all cases, including an overhanging lead acrylic shield positioned over the patient's midabdomen (upper body shield), a lead apron skirt extending parallel to the fluoroscopy table on the side of the operator (lower body shield), and an approximately $2 \times 1 \mathrm{~m}$ mobile barrier placed in front of the primary operator perpendicular to the angiography table. In addition, a disposable radiationabsorbing surgical drape (RADPAD; Worldwide Innovations \& Technologies, Lenexa, Kansas), which has proved efficacious in reducing physician exposure during interventional cardiology and vascular interventional radiology procedures, was randomly selected to be used in half of cases. ${ }^{23-31}$ If selected for use, the radiation protection drape was initially placed on the patient's right thigh below the femoral sheath insertion site and was subsequently transferred to the right lower abdomen once the catheter had been advanced into the thoracic aorta (Fig 1).

In the second half of the study, radiation exposure was again measured during 60 additional consecutive neuroangiography procedures performed in the same biplane angiosuite. However, in this portion of the study, the electronic dosimeter was placed at the collar level on an IV pole located on the opposite side of the angiosuite table immediately across from the primary operator and standard lead shielding. This step was to simulate operator exposure when lead shielding is not used because it was thought unethical to remove lead shielding from the side of the operator. Once again, a radiation protection drape was randomly selected for use in half of cases, this time positioned over the left lower abdomen. The dosimeter remained in the angiosuite throughout the procedure, including during power-injected DSA runs.

Operator radiation exposure was then analyzed according to the presence or absence of lead shielding and the radiation protection drape, yielding 4 groups (Table 1). One-way ANOVA was initially performed to test whether there were any group differences in procedure PKA, fluoroscopy time, and patient BMI. The Pearson correlation was used to analyze the simple relationship between operator radiation exposure and procedure PKA, fluoroscopy time, and patient BMI. Two-way analysis of covariance was performed to test the effect of lead shielding and the radiation protection drape on operator exposure, controlling for $\geq 1$ of the other covariates (PKA, fluoroscopy time, patient BMI). Covariates were selected on the basis of whether they were significant explanatory variables in the multiple linear regression model with exposure dose as the response. A post hoc test with a Tukey correction was then performed to test for group differences in exposure dose, while controlling for the covariates. All statistical analysis was performed by using the computing environment $\mathrm{R}$ statistical and computing software (Version 3.2.0) (http://www. r-project.org). $P<.05$ was considered statistically significant.

\section{RESULTS}

Data were successfully collected from all eligible neurointerventional examinations in 2 blocks of 60 consecutive procedures. In 


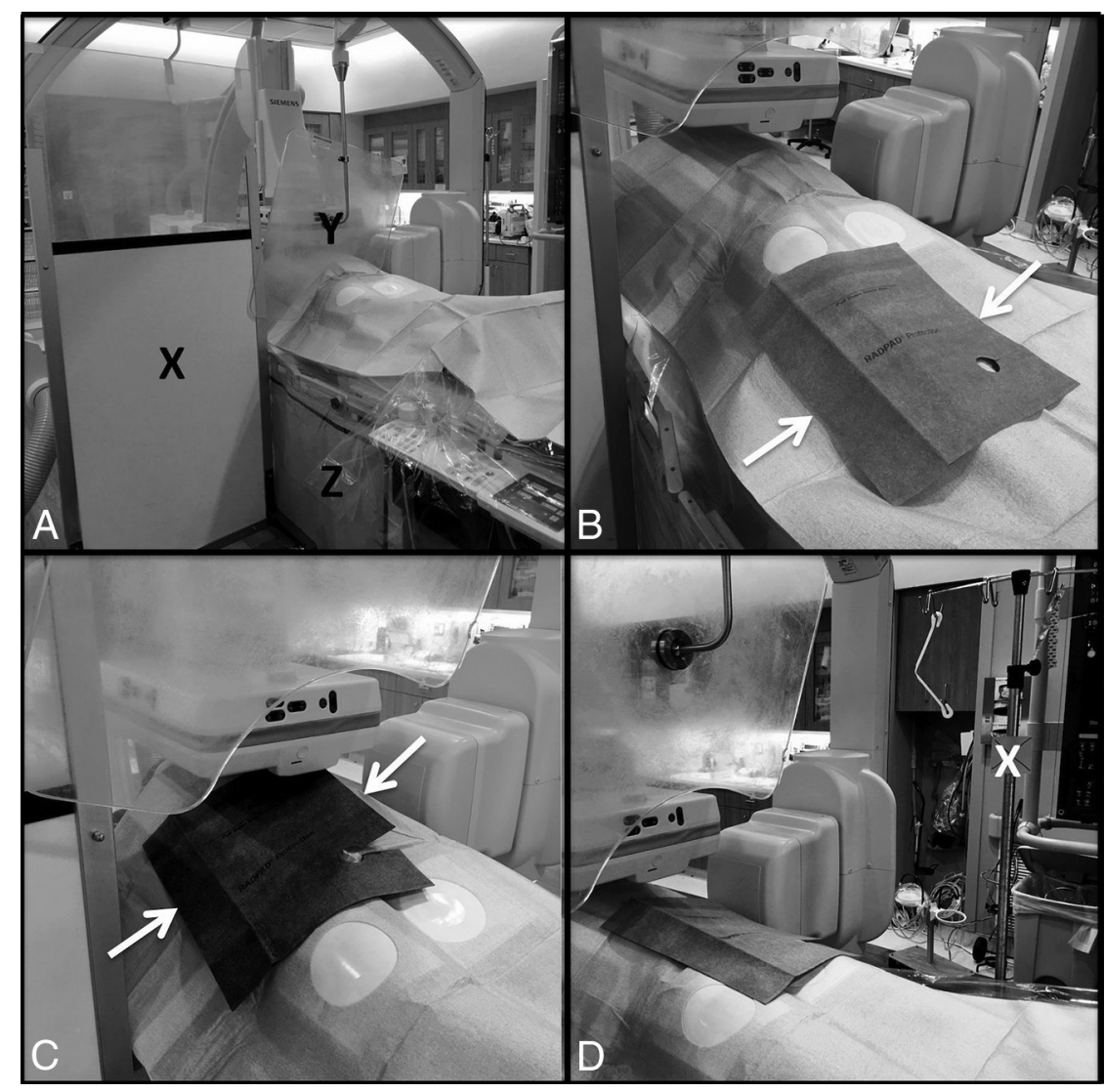

FIG 1. Configuration of shielding systems and dosimeter in the angiosuite. $A$, Positions of the mobile barrier $(X)$, upper body shield $(Y)$, and lower body shield $(Z)$ are noted. B, Position of the radiation protection drape (white arrows) before sheath insertion and advancement of the diagnostic/intermediate catheter into the thoracic aorta. C, Position of the radiation protection drape (white arrows) during the remainder of the procedure. D, Position of the dosimeter (white $X)$ in the second block of 60 patients, attached to an IV pole. The radiation protection drape is positioned over the left side of the patient.

Table 1: Shielding system groups

\begin{tabular}{lcc}
\hline Group & $\begin{array}{c}\text { Radiation } \\
\text { Protection Drape }\end{array}$ & $\begin{array}{c}\text { Standard Lead } \\
\text { Shielding Systems }\end{array}$ \\
\hline ROLO & - & - \\
RILO & + & - \\
ROL1 & - & + \\
RIL1 & + & + \\
\hline
\end{tabular}

Note:-ROLI indicates standard lead shielding; ROLO, no shielding; RILO, use of the RADPAD drape; RILI, concomitant use of the 2 shielding systems together; +, present; -, absent.

total, 71 diagnostic and 49 interventional neuroangiography procedures were included. During the initial investigation of operator radiation exposure data, 1 diagnostic procedure was excluded from further analysis due to a reported high operator exposure dose, which was out of proportion to the procedure PKA. This outlier may have occurred due to either improper dosimeter positioning or erroneous data entry. Consequently, data from 70 diagnostic and 49 therapeutic neurointerventional angiography procedures were included for further analysis (Table 2).

Mean operator radiation dose per procedure in the entire cohort was $20.6 \pm 1.6 \mu \mathrm{Sv}$ and $17.7 \pm 1.4 \mu \mathrm{Sv}$ for the 89 procedures in which exposure was measured by using some type of shielding system. The mean fluoroscopy time and PKA for the entire cohort were $44.6 \pm$ 47.3 minutes and $149.3 \pm 90.1 \mathrm{~Gy} \times \mathrm{cm}^{2}$, respectively. Compared with therapeutic interventions, diagnostic examinations were associated with shorter fluoroscopy times $(17.5 \pm 1.4$ minutes versus $83.3 \pm 51.0$ minutes, $P<.0001)$ and lower PKA $\left(132 \pm 88 \mathrm{~Gy} \times \mathrm{cm}^{2}\right.$ versus $\left.174 \pm 88 \mathrm{~Gy} \times \mathrm{cm}^{2}, P=.014\right)$. The mean patient body mass index was 28.2 (range, 15.2-50.1).

One-way ANOVA testing demonstrated no statistically significant differences in the ratio of diagnostic-versusinterventional procedures $(F=0.86$, $P=.47)$, mean fluoroscopy time $(F=$ 0.433, $P=.73)$, mean PKA $(F=0.53$, $P=.67)$, or mean patient BMI (ANOVA, $F=2.36, P=.08$ ) among the 4 shielding groups. Two-way analysis of the covariance showed that operator radiation exposure was highly correlated with procedure PKA, regardless of the shielding systems used $(r=0.59, P<$ $.0001)$. Although fluoroscopy time $(r=$ $0.29, P=.0013)$ and patient BMI $(r=$ $-0.17, P=.062)$ also correlated with operator radiation exposure, these covariates were no longer significant after taking PKA into account. Consequently, only PKA was included as a covariate in the final ANCOVA model for the effects of shielding systems on operator exposure dose.

ANCOVA revealed that the use of lead shielding $(F=12.54, P<.0001)$ and the radiation protection drape $(F=$ 7.02, $P=.009)$ significantly reduced operator exposure after adjusting for procedure PKA (Table 3 ). Post hoc tests comparing the adjusted operator exposure dose for the 4 shielding groups indicated that standard lead shielding (R0L1) reduced operator exposure to scatter radiation by nearly half $(45 \%)$ compared with no shielding (R0L0) $(P<.001)$. Use of the RADPAD drape (R1L0) was also associated with a significant but smaller reduction in operator exposure $(29 \%)(P=.026)$. Finally, the concomitant use of the 2 shielding systems together (R1L1) failed to further reduce operator exposure to scatter radiation. The R1L1 group demonstrated a $44 \%$ reduction in operator exposure compared with no shielding (R0L0), essentially identical to standard lead shielding alone (R1L1 versus R0L1, $P=.99$ ).

\section{DISCUSSION}

Our results demonstrate that the consistent use of standard lead shielding can reduce the exposure of neurointerventionalists to scatter radiation by as much as $45 \%$. More surprising is the $29 \%$ reduction in exposure afforded by the radiation protection drape. Although the drape had previously been shown to be effective in interventional cardiology and vascular interventional radiology procedures, physicians in these specialties often stand much closer to the irradiated portion of the patient's body, for example, 
Table 2: Baseline group characteristics

\begin{tabular}{|c|c|c|c|c|}
\hline $\begin{array}{l}\text { Shielding } \\
\text { Group }\end{array}$ & $\begin{array}{c}\text { Mean } \\
\text { FT (min) }\end{array}$ & $\begin{array}{l}\text { Mean PKA } \\
\left(G y \times \mathrm{cm}^{2}\right)\end{array}$ & $\begin{array}{c}\text { Mean } \\
\text { Patient BMI }\end{array}$ & Intervention/Diagnostic \\
\hline ROLO & 41.63 & 148.43 & 25.9 & $12 / 18$ \\
\hline RILO & 37.38 & 138.64 & 29.74 & $9 / 21$ \\
\hline ROL1 & 54.08 & 164.11 & 29.48 & $14 / 16$ \\
\hline RIL1 & 45.17 & 145.74 & 27.35 & $14 / 15$ \\
\hline
\end{tabular}

Note:-FT indicates fluoroscopy time; ROL1, standard lead shielding; ROLO, no shielding; RIL0, use of the RADPAD drape; RIL1, concomitant use of the 2 shielding systems together.

Table 3: Operator dose and adjusted dose reduction relative to ROLO

\begin{tabular}{lcccc}
\hline $\begin{array}{c}\text { Shielding } \\
\text { Group }\end{array}$ & $\begin{array}{c}\text { Mean } \\
\text { Operator } \\
\text { Dose }(\boldsymbol{\mu} \text { Sv) }\end{array}$ & $\begin{array}{c}\text { Standard } \\
\text { Error }\end{array}$ & $\begin{array}{c}\text { Dose Relative } \\
\text { to ROL0: } \\
\text { Adjusted for PKA }\end{array}$ & Significance \\
\hline ROLO & 29.1 & 0.212 & NA & NA \\
RIL0 & 19.5 & 0.211 & 0.78 & $P<.001$ \\
ROL1 & 17.7 & 0.211 & 0.55 & $P=.026$ \\
RIL1 & 15.9 & 0.213 & 0.56 & $P<.001$ \\
\hline
\end{tabular}

Note:-NA indicates not applicable; ROL1, standard lead shielding; ROLO, no shielding; RILO, use of the RADPAD drape; RIL1, concomitant use of the 2 shielding systems together.

next to the thorax during cardiac pacemaker/defibrillator placement. In these instances, the drape is placed directly adjacent to the irradiated body part, where it is in an optimal position to shield the operator from scatter radiation. In contradistinction, neurointerventionalists using femoral artery access typically stand much farther away from the x-ray target (ie, head and neck), and it was uncertain whether placing the drape over the patient's lower abdomen would still be effective. However, despite the greater distance between operator and $\mathrm{x}$-ray source, the drape still significantly reduced operator exposure.

The current study failed to show a further reduction in operator dose when augmenting lead shielding with the radiation protection drape. However, we still use the inexpensive, easy-to-use drape in our practice because we believe it may provide additional radiation protection in certain situations. These include procedures requiring greater radiation exposure of the pelvis (eg, difficult femoral artery access, femoral artery injury), spinal angiography, and studies using brachial or radial artery access. Although not evaluated in the current study, the drape may be more effective in these instances due to a combination of increased proximity of the operator to the irradiated body part and an inability to optimally position all lead shielding components. For example, the overhanging lead shield is impractical to use during femoral sheath insertion, while the stand-alone lead shield is similarly unworkable when using a brachial artery approach.

Furthermore, although we consistently use extensive lead shielding in our practice, this is likely not the case for all neurointerventionalists. Overhanging and stand-alone lead shielding can be cumbersome to use, particularly during complex interventions such as aneurysm coiling, which often require oblique positioning of the fluoroscopy tubes. In these instances, the working space available for lead shields is often reduced, making them difficult or impractical to use. Moreover, some practices may be limited in their use of lead shielding, either because it is not readily available or due to physical constraints within the angiography suite. In situations in which lead shielding is not ideal, either due to operator preference or limitations of a particular practice, a radiation protection drape may be a reasonable alternative for scatter radiation protection.
Operator exposure was highly correlated with PKA. As discussed in the "Materials and Methods" section, procedure PKA is a reasonable measure of overall procedure complexity, potentially accounting for a diverse array of difficult-toanticipate variables, including intervention type, experience of the operators, vessel tortuosity, and vessel plaque burden. After we accounted for this correlation, neither procedure type nor patient BMI significantly impacted operator dose. Before the current study, we had speculated that patient BMI might impact operator exposure secondary to increased scatter radiation production while imaging over the superiormost aspect of the thorax and lower neck. The latter occurs during catheterization of cervical vessels and can represent a significant percentage of procedure time in diagnostic cerebral angiograms, particularly with tortuous vessel anatomy. However, any increase in scatter radiation generated by larger size patients was too small to be detected.

Operator exposure was modest in the current study: $20.6 \mu$ Sv per procedure for the entire cohort and $17.7 \mu \mathrm{Sv}$ when using some types of shielding. Given these results, it is highly unlikely that an operator in our practice would exceed the annual occupational limit of 20 $\mathrm{mSv}$. Although comparison with prior studies can be challenging due to differences in methodology, other authors have typically noted higher operator doses during neurointerventional procedures. For example, Moritake et $\mathrm{al}^{5}$ reported an average entrance dose at the operator's left collar of $50 \mu \mathrm{Gy} / \mu \mathrm{Sv}$ ( $n=32)$, Kemerink et $\mathrm{al}^{2}$ found an average entry dose at the operator's neck of $74 \mu \mathrm{Gy} / \mu \mathrm{Sv}(n=31)$, and Bor et $\mathrm{al}^{18}$ noted a mean entry dose of $28.8 \mu \mathrm{Gy} / \mu \mathrm{Sv}$ in the region of the thyroid $(n=57)$. We believe that the meticulous use of shielding systems in most of our cases contributed to the relatively low operator exposure, though other factors, including fluoroscope settings, likely played a role.

The current study has several limitations, which reflect some of the practical challenges of measuring operator radiation exposure during everyday clinical practice. First, our measured operator dose likely overestimates true physician exposure during clinical practice secondary to leaving the dosimeter in the angiosuite during powerinjected DSA runs. However, this practice allowed us to standardize the relationship between measured operator exposure and procedure PKA. In addition, estimated operator exposure in the second half of the study may have been slightly greater than in the first half due to the dosimeter being located on the side of the lateral fluoroscope $\mathrm{x}$-ray source. This feature, in turn, may have led to a mild overestimation of the efficacy of lead shielding. However, the difference was thought likely to be small because the lateral tube is almost exclusively used when imaging over the head and upper neck, where the greater distance of the operator/dosimeter from the irradiated body part would likely minimize any such variation. Finally, small variations in positioning of the dosimeter during the first half of the study, when operators wore the dosimeter, may have also affected our results. However, it was not practical to attach the dosimeter to a fixed position such as an IV pole on the right side of the angiosuite table because it would have interfered with the work of physician operators. Despite these issues, our results help to quantify the degree of protection afforded by shielding systems in neurointerventional 
surgery and have demonstrated that such systems may help limit physician exposure to acceptable levels in a modern neurointerventional practice.

\section{CONCLUSIONS}

Extensive lead shielding should be used as much as possible in neurointerventional surgery to reduce operator radiation exposure to acceptable levels. A radiation protection drape is a reasonable alternative when standard lead shielding is unavailable or impractical to use without neglecting strategies to minimize the dose.

Disclosures: Timothy R. Miller-UNRELATED: Grants/Grants Pending: University of Maryland, Comments: Medtronic industry grant for already published research pertaining to comparison of the classic-versus-second-generation Flex Pipeline Embolization Device paid to University of Maryland Medical Center Radiology Department; Stryker industry grant for the Trevo Retriever Registry Post Market Surveillance paid to the University of Maryland Medical Center Radiology Department; Medtronic industry grant for Apollo, Onyx, Delivery Micro Catheter Post Market Safety Study paid to the University of Maryland Medical Center Radiology Department; Pending: MicroVention industry grant for the Pivotal Study of the FRED Stent System in the Treatment of Intracranial Aneurysms paid to the University of Maryland Medical Center Radiology Department.* Gaurav Jindal-UNRELATED: Grants/Grants Pending: Stryker, MicroVention, Codman, Medtronic, Comments: research grants*; Payment for Lectures including Service on Speakers Bureaus: Internal Medicine Department at the Union Memorial Hospital in Baltimore, Maryland. Dheeraj Gandhi-UNRELATED: Royalties: Cambridge Press. *Money paid to the institution.

\section{REFERENCES}

1. Sans Merce M, Korchi AM, Kobzeva L, et al. The value of protective head cap and glasses in neurointerventional radiology. J Neurointerv Surg 2016;8:736-40 CrossRef Medline

2. Kemerink GJ, Frantzen MJ, Oei K, et al. Patient and occupational dose in neurointerventional procedures. Neuroradiology 2002;44: 522-28 CrossRef Medline

3. Tavares JB, Sacadura-Leite E, Matoso T, et al. The importance of protection glasses during neuroangiographies: a study on radiation exposure at the lens of the primary operator. Interv Neuroradiol 2016;22:368-71 CrossRef Medline

4. Layton KF, Kallmes DF, Cloft HJ, et al. Radiation exposure to the primary operator during endovascular surgical neuroradiology procedures. AJNR Am J Neuroradiol 2006;27:742-43 Medline

5. Moritake T, Matsumaru Y, Takigawa T, et al. Dose measurement on both patients and operators during neurointerventional procedures using photoluminescence glass dosimeters. AJNR Am J Neuroradiol 2008;29:1910-17 CrossRef Medline

6. Lekovic GP, Kim LJ, Gonzalez LF, et al. Radiation exposure during endovascular procedures. Neurosurgery 2008;63:ONS81-85; discussion ONS85-86 Medline

7. Alexander MD, Oliff MC, Olorunsola OG, et al. Patient radiation exposure during diagnostic and therapeutic interventional neuroradiology procedures. J Neurointerv Surg 2010;2:6-10 CrossRef Medline

8. Committee on Health Effects of Exposure to Low Levels of Ionizing Radiations. Health Effects of Exposure to Low Levels of Ionizing Radiations: Time for Reassessment? National Academy Press: Washington, DC; 1998

9. Thierry-Chef I, Simon SL, Land CE, et al. Radiation dose to the brain and subsequent risk of developing brain tumors in pediatric patients undergoing interventional neuroradiology procedures. $\mathrm{Ra}$ diat Res 2008;170:553-65 CrossRef Medline

10. Orbach DB, Stamoulis C, Strauss KJ, et al. Neurointerventions in children: radiation exposure and its import. AJNR Am JNeuroradiol 2014;35:650-56 CrossRef Medline

11. Venneri L, Rossi F, Botto N, et al. Cancer risk from professional exposure in staff working in cardiac catheterization laboratory: insights from the National Research Council's Biological Effects of Ionizing Radiation VII Report. Am Heart J 2009;157:118-24 CrossRef Medline

12. Amis ES Jr, Butler PF, Applegate KE, et al; American College of Radiology. American College of Radiology white paper on radiation dose in medicine. J Am Col Radiol 2007;4:272-84 CrossRef Medline
13. Vano E, Fernandez JM, Sanchez RM, et al. Patient radiation dose management in the follow-up of potential skin injuries in neuroradiology. AJNR Am J Neuroradiol 2013;34:277-82 CrossRef Medline

14. Peterson EC, Kanal KM, Dickinson RL, et al. Radiation-induced complications in endovascular neurosurgery: incidence of skin effects and the feasibility of estimating risk of future tumor formation. Neurosurgery 2013;72:566-72 CrossRef Medline

15. Roguin A, Goldstein J, Bar O. Brain tumours among interventional cardiologists: a cause for alarm? Report of four new cases from two cities and a review of the literature. EuroIntervention 2012;7: 1081-86 CrossRef Medline

16. Roguin A, Goldstein J, Bar O, et al. Brain and neck tumors among physicians performing interventional procedures. Am J Cardiol 2013;111:1368-72 CrossRef Medline

17. Chohan MO, Sandoval D, Buchan A, et al. Cranial radiation exposure during cerebral catheter angiography. J Neurointerv Surg 2014; 6:633-36 CrossRef Medline

18. Bor D, Cekirge S, Türkay T, et al. Patient and staff doses in interventional neuroradiology. Radiat Prot Dosimetry 2005;117:62-68 Medline

19. Kahn EN, Gemmete JJ, Chaudhary N, et al. Radiation dose reduction during neurointerventional procedures by modification of default settings on biplane angiography equipment. J Neurointerv Surg 2016;8:819-23 CrossRef Medline

20. Schneider T, Wyse E, Pearl MS. Analysis of radiation doses incurred during diagnostic cerebral angiography after the implementation of dose reduction strategies. J Neurointerv Surg 2016 Apr 7. [Epub ahead of print] CrossRef Medline

21. Pearl MS, Torok C, Wang J, et al. Practical techniques for reducing radiation exposure during cerebral angiography procedures. $J \mathrm{Neu}$ rointerv Surg 2015;7:141-45 CrossRef Medline

22. Honarmand AR, Shaibani A, Pashaee T, et al. Subjective and objective evaluation of image quality in biplane cerebral digital subtraction angiography following significant acquisition dose reduction in a clinical setting. J Neurointerv Surg 2016 Apr 6. [Epub ahead of print] CrossRef Medline

23. Simons GR, Orrison WW Jr. Use of a sterile, disposable, radiationabsorbing shield reduces occupational exposure to scatter radiation during pectoral device implantation. Pacing Clin Electrophysiol 2004;27:726-29 CrossRef Medline

24. Sawdy JM, Gocha MD, Olshove V, et al. Radiation protection during hybrid procedures: innovation creates new challenges. J Invasive Cardiol 2009;21:437-40 Medline

25. Power S, Mirza M, Thakorlal A, et al. Efficacy of a radiation absorbing shield in reducing dose to the interventionalist during peripheral endovascular procedures: a single centre pilot study. Cardiovasc Intervent Radiol 2015;38:573-78 CrossRef Medline

26. Politi L, Biondi-Zoccai G, Nocetti L, et al. Reduction of scatter radiation during transradial percutaneous coronary angiography: a randomized trial using a lead-free radiation shield. Catheter Cardiovasc Interv 2012;79:97-102 CrossRef Medline

27. Murphy JC, Darragh K, Walsh SJ, et al. Efficacy of the RADPAD protective drape during real world complex percutaneous coronary intervention procedures. Am J Cardiol 2011;108:1408-10 CrossRef Medline

28. Kloeze C, Klompenhouwer EG, Brands PJ, et al. Editor's choice-Use of disposable radiation-absorbing surgical drapes results in significant dose reduction during EVAR procedures. Eur J Vasc Endovasc Surg 2014;47:268-72 CrossRef Medline

29. King JN, Champlin AM, Kelsey CA, et al. Using a sterile disposable protective surgical drape for reduction of radiation exposure to interventionalists. AJR Am J Roentgenol 2002;178:153-57 CrossRef Medline

30. Jones MA, Cocker M, Khiani R, et al. The benefits of using a bismuth-containing, radiation-absorbing drape in cardiac resynchronization implant procedures. Pacing Clin Electrophysiol 2014;37: 828-33 CrossRef Medline

31. Germano JJ, Day G, Gregorious D, et al. A novel radiation protection drape reduces radiation exposure during fluoroscopy guided electrophysiology procedures. J Invasive Cardiol 2005;17:469-72 Medline 